\title{
XL. The contact difference of potential of distilled metals
}

\section{A.LI. Hughes B.A. D.Sc.}

To cite this article: A.LI. Hughes B.A. D.Sc. (1914) XL. The contact difference of potential of distilled metals, Philosophical Magazine Series 6, 28:165, 327-347, DOI: 10.1080/14786440908635217

To link to this article: http://dx.doi.org/10.1080/14786440908635217

曲 Published online: 08 Apr 2009.

Submit your article to this journal $₫$

Џ Article views: 3

Q View related articles $\square$

Citing articles: 4 View citing articles 5 
Rutherford and Robinson* have found a few $\beta$ particles from radium $C$ carrying as much as $3.9 \times 10^{-6} \mathrm{erg}$.

Similarly the fastest $\beta$ ray observed from radium $B$ has an energy of $6 \times 10^{-6} \mathrm{erg}$, while a very rough approximation to the combined energy of the $\beta$ and $\gamma$ radiations gives $.7 \times 10^{-5} \mathrm{erg}$.

The results in the case of radium $C$ are thus at variance with the theory, but the discrepancy is hardly greater than can be explained by the uncertainty in the exact value of the heat produced by the $\gamma$ radiation, and in other factors in the calculations.

We wish to thank Sir Ernest Rutherford, who suggested the work, for his advice and interest during its progress.

Physical Laboratory, University of Manchester.

XL. The Contact Difference of Potential of Distilled Metals. By A. Lr. Hughes, B.A., D.Sc., Assistant Professor of Physics, The Rice Institute, Houston, 1exast.

THIS paper contains a short account of some experiments 1 on the contact difference of potential between metals and particularly on its relation to the presence or absence of occluded gases. The research was suggested by a comparison of the photo-electric experiments of Richardson and Compton with those carried out by the writer. A discussion of the relations between photo-electricity and contact difference of potential will be given before the actual experiments are described.

One of the most important problems in photo-electricity is the determination of the exact relation between the maximum emission velocity of the photo-electrons and the frequency of the light causing their emission. Experimental difficulties made it impossible, until recently, to determine the exact way in which the velocity increased with the frequency. The relation between the two quantities has been shown by Richardson and Compton $\ddagger$, and by the writer $\S$ to be that the velocity squared, or the energy, of the fastest photoelectrons is a linear function of the frequency. This is generally expressed in the form

$$
\mathrm{V}=k n-\mathrm{V}_{0}, \text {. . . . . . }
$$

where $V$ is the potential just necessary to stop the electron

* Rutherford and Robinson, Phil. Mag. xxvi. p. 717 (1913).

+ Communicated by the Author.

I Richardson and Compton, Phil. Mag. xxiv. p. 575 (1912).

$\$$ Hughes, Phil. Trans. A. cexii. p, 205 (1912).

Phil. Mag. S. 6. Vol. 28. No. 165. Sept. 1914. 
and therefore proportional to its energy, $n$ the frequency, and $k$ and $\mathrm{V}_{0}$ are constants. $\mathrm{V}_{0}$ varies from metal to metal, while $k$ is almost independent of the nature of the metal. In a theoretical discussion * of the photo-electric effect, Richardson has identified $V_{0}$ with the "intrinsic potential" of the metal. The meaning of this may be made clear in the following way. If $V_{0}(C u)$ be the value of $V_{0}$ for copper and $V_{0}(Z n)$ be that for zinc, then $V_{0}(Z n)-V_{0}(C u)$ obtained from photo-electric experiments should be identical with the contact difference of potential between the metals.

Quite recently, some very interesting results, which may lead to a more definite linowledge of the nature of photoalectricity, have been obtained by a number of investigators. Küstner $\hat{\dagger}$ found that no photo-electric effect is shown by zinc when it has been scraped in a vacuum after extraordinary precautions have been made to exclude gases, particularly active ones. (The shortest wave-length available in these experiments was probably $\lambda$ 1850.) Wiedmann and Hallwachs $\ddagger$ found that the removal of occluded gases from potassium by repeated distillation in a very high vacuum caused its photo-electric effect to disappear completely. (Since the light had to pass through glass, the shortest wavelength was probably about $\lambda$ 3400.) These results were confirmed by Fredenhagen $\S$. On the other hand, Pohl and Pringsheim || found that potassium behaved in practically the same way whether it was freed from gases by repeated distillation in a very good vaeum or prepared in the usual way for photo-electric cells. We cannot therefore regard the suppression of the photo-electric effect by the removil of gases from the metallic surfaces as established beyond dispute. Nevertheless, the results are of great interest. It is implied in the papers of Wiedmann and Hallwachs, Fredenhagen, and Küstner, that the photo-electric effect does not exist when occluded gases are completely removed from the metal. A less violent departure from current views would be to regard the experiments as indicating that $V_{0}$ in equation (1) is increased to such a value that light of the wave-lengths available in their experiments is no longer capable of exciting the photo-electric effect. The law expressed by equation (1) holds not only for the electrons released by light from metalle

- Richardson, Phil. Mag. Xxiv. p. 570 (1912); Richardson and Compton, Phil. Mag. xxvi. p. 550 (1913).

+ Küstner, Phys. Zeits. p. 68 (1914).

‡ Wiedmann and Hallwachs, Verh. d. Deutsch. Phys. Ges. p. 107 (1914).

§ Fredenhagen, Verh.d. Deutsch. Phys. Ges. p. 201 (1914).

II Pohl and Pringsheim, Verh. d. Deutsch. Phys. Ges. p. 336 (1914). 
surfaces, but also for high-speed electrons released by Röntgen rays. Consequently, it may be inferred that the processes of emission of electrons from metals by light and by Röntgen rays have much in common. There is not the slightest evidence for believing that the emission of high-speed electrons from metals struck by Röntgen rays, depends in any way upon the presence of occluded gases, and consequently we should not expect the photo-electric effect to depend, directly at least, upon the gases in the surface. The value of $\nabla_{0}$ may be a function of the amount of gas absorbed in the surface, and on this view the complete removal of occluded gases may cause $V_{0}$ to increase to such a value that the long wave-length limit of the photo-electric effect is beyond the part of the spectrum used by the investigators.

Ever since contact differeuce of potential between metals was first observed, two essentially different theories as to its nature have been advanced by physicists and, as yet, no experiments have been made which can be said to support one and disprove the other. According to one theory, two metals in contact are at different potentials; on this theory the contact potential is a specific property of the metal itself. The other theory maintains that the difference of potential observed is the difference of potential between the gaseous films on the surfaces of the metals and not between the metals themselves. The difference of potential between the film and the metal depends upon the nature of the metal and on the gas, and hence this theory may be called the chemical theory of contact potential. The great difficulty of removing or altering the exceedingly tenacious films of gas which adhere to metallic surfaces as soon as they are exposed to air, has been an obstacle in the way of obtaining definite information as to the nature of contact potential.

The novel feature about the experiments described in this paper is that the metals were prepared by distillation in vacuo, and measurements of the contact potential were made before the metals had been exposed to air at any appreciable pressure. The apparatus used is shown in fig. 1 . The base is a brass plate about $35 \mathrm{~cm}$. in diameter and $6 \mathrm{~mm}$. thick. Through the centre passes a vertical steel rod or spindle, which is turned down to a point at the upper end. $\Lambda$ plate glass disk $G$ with a circular hole in the middle is supported by a brass cap $\mathrm{C}$, which in turn rests on the steel spindle in such a way that the cap and disk can rotate freely. The position of the disk was controlled magnetically from outside. An almost opaque film of platinum was deposited on the under side of the glass disk from a platinum cathode. 
(This was done in another apparatus.) The film was generally exposed to the atmosphere for about two days before contact potential experiments were made. Two quartz furnaces, F, which could be heated electrically, are situated

Fig. 1.

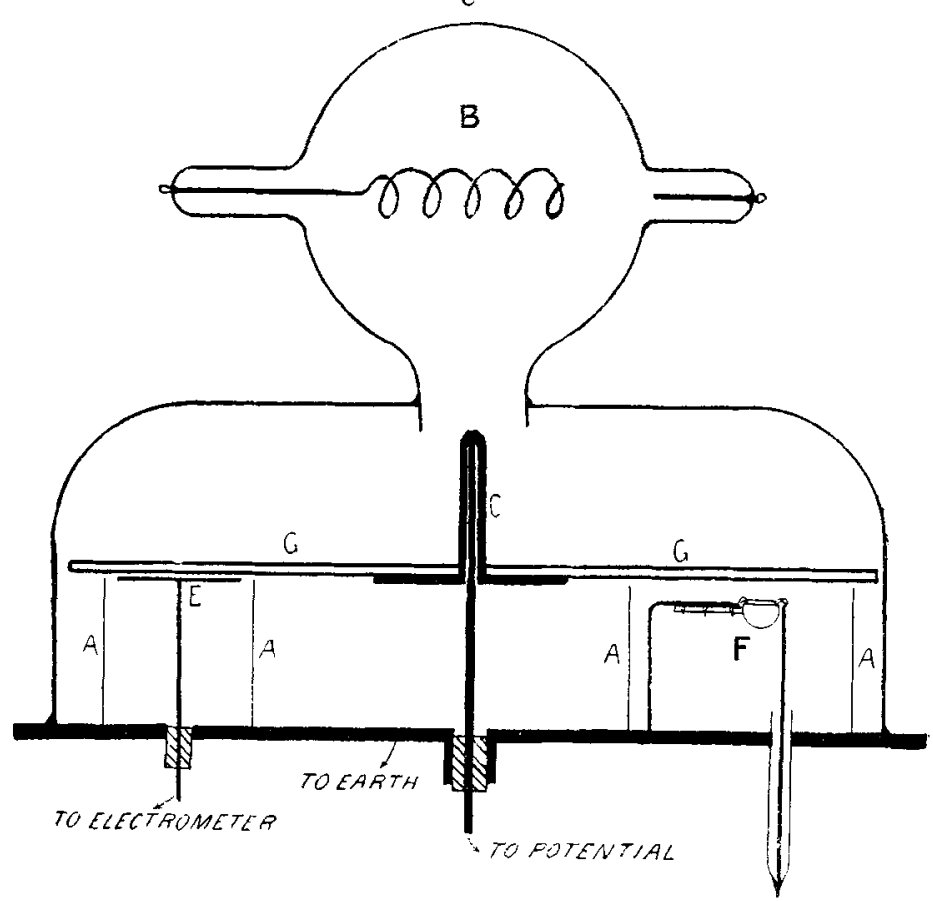

below the glass disk and in positions making an angle of $120^{\circ}$ with one another and with the brass electrode E. One contained bismuth and the other, zinc. The furnaces with the metals in them were heated beforehand for a considerable time in an auxiliary vacuum to get rid of occluded gases as much as possible. The distilled metals were deposited on the under side of the glass disk. The partitions $A$, surrounding the furnaces and the electrode $\mathbf{E}$, served to confine the deposit to definite areas of the disk. The distance between the disk and the electrode $\mathrm{E}$ was about $1 \mathrm{~mm}$. This electrode was connected to a quadrant electrometer whose sensitiveness was 700 divisions per volt. The apparatus was exhausted by means of a Gaede molecular airpump, to which it was joined by a short brass tube about $25 \mathrm{~mm}$. wide. All joints were made airtight by a mixture 
of beeswax and resin which had boen subjected to prolonged heating to drive off vapours. The bulb $\mathrm{B}$, provided with electrodes, served to test the vacuum during the course of the experiments. Its diameter was about $15 \mathrm{~cm}$.

The method of experiment was as follows :-The electrode E connected to the electrometer, previously earthed, was insulated. Then the disk, connected to earth through the spindle, was rotated. Since the disk is always equidistant from $\mathrm{E}$, no change will take place in the deflexion of the electrometer as the disk is rotated, provided that the portion of the disk opposite $\mathbf{E}$ is always of the same metal. But if a part of the disk covered by another metal comes opposite to $\mathbf{E}$, the deflexion of the electrometer will alter. By applying a suitable potential to the disk (through the spindle), the deflexion can be brought back to its original value. The potential necessary to do this is the contact difference of potential between the two metals on the disk. The method was tested by electroplating a brass disk of the same size as the glass disk with copper on one part and zine on the other, and measuring the contact difference of potential between them. It was found to be $\cdot 75$ volt, which a grees well with the values given by other methods.

Two typical sets of results will be given. The apparatus was exhausted by means of the molecular pump. After about 15 minutes, a patch of zinc was distilled on to a portion of the disk. The contact potential between this patch and the rest of the platinnm surface was measured as described above.
(a) $\left\{\begin{array}{c}2 \text { mins. after } \\ \text { distillation } \\ 10 \text { mins. later. }\end{array}\right.$
$\begin{gathered}\text { Zn electropositive } \\ \text { to Pt by }\end{gathered}$
$"$

Air was then admitted to the "rough vacuum" of the molecular pump to a pressure of $1 \mathrm{~cm}$.
(b) $\left\{\begin{array}{lll} & \\ 5 & \text { mins. later. } \\ 5 & , & , \\ 5 & " & , \\ 5 & :, & , \\ 5 & , & ,\end{array}\right.$
$\left.\begin{array}{l}\text { Zn electropositive } \\ \text { to } \mathrm{Pt} \text { by }\end{array}\right\} \cdot 60$ volt.

$\begin{array}{lll}, " & .79 & , \\ , & .87 & ", \\ , & .92 & ", \\ , & .86 & , \\ , & .80 & \end{array}$

Rough vacuum pumped out.
(c) $\left\{\begin{array}{llc}5 & \text { mins later. } \\ 5 & , & \\ 5 & , & , "\end{array}\right.$
$\begin{array}{cc}\begin{array}{c}\text { Zn electropositivo } \\ \text { to } \mathrm{Pt} \text { by }\end{array} & \cdot 81 \text { volt. } \\ ", & 83 \\ " & .87\end{array}$ 
Air was admitted to the rough vacuum of the molecular pump to a pressure of $2 \mathrm{~cm}$.
(d) $\left\{\begin{array}{c}- \\ 5 \text { mins. later, }\end{array}\right.$
$\left.\begin{array}{c}\text { Zn electropositive } \\ \text { to } \mathrm{Pt} \text { by }\end{array}\right\} \begin{aligned} & 79 \text { volt. } \\ & \cdot 66\end{aligned}$

Rough vacuum pumped out as before.
(e) $\left\{\begin{array}{c}- \\ 5 \text { mins. later. }\end{array}\right.$
$\left.\begin{array}{l}\text { Zn electropositive } \\ \text { to } P t \text { by }\end{array}\right\} \begin{aligned} & 76 \text { rolt. } \\ & .80\end{aligned}$

Air admitted to the rough vacuum to a pressure of $10 \mathrm{~cm}$. and then pumped out.

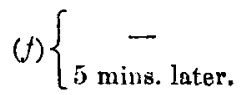

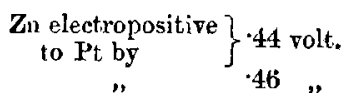

Air at atmospheric pressure admitted to apparatus.
(g) $\{20$ hours later.
$\left.\begin{array}{l}\text { Zn electropositive } \\ \text { to Pt by }\end{array}\right\} \cdot 38$ volt.

Apparatus pumped out cornpletely.
(h) $\left\{\begin{array}{c}- \\ 50 \text { mins. later. }\end{array}\right.$
$\left.\begin{array}{c}\begin{array}{c}\text { Zn electropositive } \\ \text { to } \mathrm{Pt} \text { by }\end{array} \\ \text { " }\end{array}\right\} \cdot 39$ volt.

Air at atmospheric pressure admitted to apparatus.
(i) $\{-$
$\left.\begin{array}{l}\text { Zn electropositive } \\ \text { to } \mathrm{Pt} \text { by }\end{array}\right\} \cdot 39^{*}$ volt.

The contact difference of potential between the zinc and the platinum immediately after the distillation of the zine is evidently quite small and increases slowly with the time $(a)$. When the pressure of the air in the apparatus is slightly raised, a great increase in the contact potential occurs (b). It is necessary to point out here how small the increase of pressure in the vacuum really is. The "rough vacuum" of the molecular pump was maintained by a Gaede box-pump giving a vacuum of about $01 \mathrm{~mm}$. On passing a discharge through the bulb $\mathrm{F}$, the alternative spark-gap was $8 \mathrm{~cm}$., which indicates a good vacuum when one considers the size of the bulb. When air at a pressure of $10 \mathrm{~mm}$. was admitted to the rough vacuum, the alternative spark-gap was reduced

* Note.-It was observed that a surface of distilled zinc after exposure to air was always more electronegative than a surface of polished zinc. Hence the structure of the surface has, directly or indirectly, a considerable effect on the contact difference of potential. 
by less than $1 \mathrm{~cm}$. Another way of considering the vacuum is as follows :-According to the information supplied with the pump, a pressure of $10 \mathrm{~mm}$. in the rough vacunm means a pressure of $\cdot 0005 \mathrm{~mm}$. in the high vacuum when the pump makes 8000 revolutions per minute. As the speed in these experiments was about 9600 revolutions per minute, it is probable that the pressure in the high vacuum was below $.0005 \mathrm{~mm}$. It is, therefore, clear that the introduction of a very small quantity of air into the apparatus causes a great change in the contact difference of potential when one of the metals has never been exposed to air before. At this stage, the conlact difference of potential is sensitive to changes in the pressure of the air. The new zinc surface is absorbing gas slowly and, up to a certain point, the contact potential difference increases with the amount of gas absorbed. The absorption of more gas caused a reduction from $\cdot 92$ to - 80 volt (observation $(b))$. From observations (c) (and also $(d),(e)$, and $(f))$, it may be inferred that the gas absorbed is not yet held very firmly, for, on reducing the pressure again, the contact difference of pressure increases. From observations $(g),(h)$, and $(i)$, we see that when the distilled metal has been in contact with air for several hours, its contact potential relative to platinum is no longer altered by changing the pressure of the gas around it, and probably the absorbed gas has become firmly attached to the metal and is not appreciably affected by the pressure of the gas in the surrounding atmosphere.

The evidence that the change in the contact potential on varying the pressure of the gas in the vacuum is localised at the surface of the distilled metal is straightforward. The deflexion of the electrometer on admitting air into the vacuum was observed, (1) when the platinum surface of the disk was opposite to the electrode $\mathrm{E}$, and (2) when the newly distilled deposit of zinc was opposite to E. No appreciable alteration in the deflexion was observed in case (1), while very considerable changes in the deflexion always occurred in case (2).

Part of another series of observations made under similar conditions is given below.
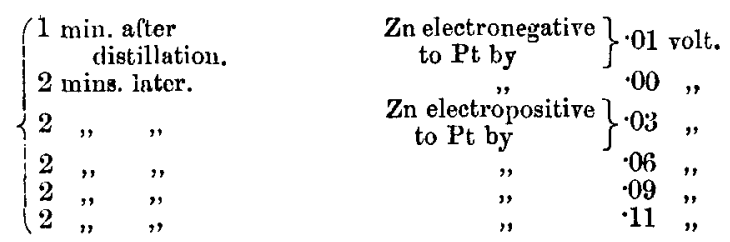
Air was then admitted to the rough vacuum of the molecular pump to a pressure of $1 \mathrm{~cm}$.

\begin{tabular}{|c|c|c|c|}
\hline \multicolumn{2}{|c|}{-} & $\begin{array}{c}\text { Zn electropositive } \\
\text { to } \mathrm{Pt} \text { by }\end{array}$ & 20 volt. \\
\hline \multicolumn{2}{|c|}{5 mins. later: } & , & \\
\hline &, & ," & $61 "$ \\
\hline & ", & $"$ & 64, \\
\hline & " & $"$ & '64, \\
\hline
\end{tabular}

The admission of air at atmospheric pressure reduced the contact potential to $: 30$ volt.

About twelve separate experiments were made on the contact difference of potential between platinum and newly distilled zinc, and results of the same character were always obtained. The newly distilled zinc was asually electropositive to the platinum film by 1 or $\cdot 2$ volt, but on a few occasions it was slightly electronegative. Even in the best vacuum obtainable in these experiments, the electropositive character of zinc invariably increased slowly, and this increase was always greatly accelerated by the admission of a trace of air. The electropositive character of zine doess not increase indefinitely; after a certain point, it decreases and reaches a steady value at which it remains and afterwards is practically independent of the pressure of the air about it. These results suggest that there is an intimate relation between the electropositive character of zinc and the amount of gas absorbed in the surface. At first, immediately after distillation, the zinc surface is almost free from absorbed gases and is strongly electronegative. Then, as it absorbs gas, it becomes more and more electropositive up to a certain point. Beyond this point, the absorption of still more gas is accompanied by a decrease in the electropositive character of the zine until a fairly constant end value is finally obtained. The principal features of the relation between the amount of gas absorbed and the electropositive character of zinc (relative to platinum) may be represented graphically as in tig. 2.

There is a close similarity between the alteration in the electropositive character of zinc on the one hand and the shifting of the long wave-length limit of its photo-electric effect on the other, as the amount of gas absorbed in the surface increases. Küstner's result that a new zinc surface, prepared in a vacuum from which all reacting gases have been excluded with the utmost care, has no photo-electric effect, has been interpreted as indicating that its long wavelength limit under these conditions is beyond $\lambda 1850$. With this result we may link an investigation by Pohl and 
Pringsheim, who did not take such elaborate precautions in preparing their vacuum. They found that the long wavelength limit of freshly distilled zine was in the ultra-violet,

Fig. 2.

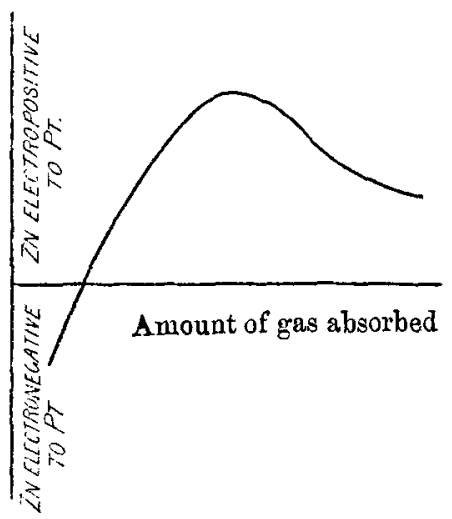

but as time went on it moved slowly into the violet and towards the red. Presumably this was due to a slight evolution of gas inside the apparatus and to its diffusion up to the zinc. The admission of air caused the long wavelength limit to move back to the violet. We may therefore conclude that both the long wave-length limit of the photoelectric effect of zinc and its electropositive character (as measured by its contact potential) alter in the same way with the amount of gas absorbed in the surface. Results of this kind are to be expected from Richardson's interpretation of $V_{0}$ in equation (1). Any process which makes a metal more electropositive (i.e. $V_{0}$ less) should, according to equation (1), be accompanied by a movement of the long wave-length limit of the photo-electric effect towards the red end of the spectrum and vice versa.

A number of experiments, similar to those already described, were made using bismuth instead of zinc. The contact difference of potential between the platinum film and the newly distilled bismuth altered with the pressure of the air in the vacuum in the same way as when zinc was used. In some experiments the bismuth and zinc were distilled simultaneously, and their contact difference of potential relative to platinum and to each other could be studied under identical conditions. The results of these experiments may be summarized by saying that bismuth is initially electronegative to zinc by about $\cdot 1$ volt, and that the change in it 


\section{Contact Difference of Potential of Distilled Metals.}

contact potential on admission of a trace of air is not quite so large as in the case of zinc.

It may be urged that the platinum in the form of a thin film deposited from a cathode on to a glass disk is not a very suitable standard for measuring the contact potential of distilled metals. From a number of experiments in which zinc was distilled on to a copper disk, there was no reason for believing that the platinum, in the form of a film on glass, was in any way abnormal. A platinum film on glass was. found to be rather more convenient than a metal disk.

It is generally agreed that for the production of the best possible vacuum, the apparatus must be exhausted continuously for several days and maintained at a high temperature for a considerable portion of that time. It was inconvenient to run the molecular pump continuously for more than a few hours and impossible to heat the apparatus on account of the wax joints. Hence although the molecular pump is an extraordinarily efficient instrument, it is probable that still better vacua could be obtained than were used in these experiments. A combination of cooled charcoal with a Gaede pump appears to be the most efficient method of completely exhausting an apparatus. However, liquid air was not available when these experiments were made and so the molecular pump alove was used. If the view of the relation of the photo-electric effect to the contact potential is correct, we should expect from Küstner's result, that zinc completely freed from gases would be still more electronegative than the distilled zinc used in these experiments. It is unlikely that the zinc distilled in these experiments was absolutely free from occluded gases, and so we may expect that further precautions would result in zinc still more electronegative in character. It was not possible to get exactly the same contact difference of potential between newly distilled zinc and platinum in different experiments made under apparently similar conditions. This is probably due to the fact that the vacuum obtained cannot be precisely the same on each occasion, and we have seen how sensitive the contact potential of new surfaces is to traces of air in the vacuum.

It seems clear from these experiments that the contact potential between metais under ordinary conditions depends to a very great extent upon the gas absorbed in the surface. The results suggest several important and interesting questions. Is there any contact difference of potential between metals completely freed from gases and, if so, how will it differ from the accepted values? Which of the gases in the air is responsible for the change in the contact. 
potential of distilled zinc and bismuth? It is not possible at this stage to offer any explanation of the precise way in which absorption of gases by the surface affects the contact potential, and indeed whether it is due to mere absorption or to something of a more definite chemical nature.

\section{Summary.}

An investigation has been made on the contact difference of potential between zinc and bismuth, both distilled in vacuo, and platinum. Initially, there is but little contact difference of potential between the distilled metal and platinum. The admission of a trace of air into the vacuum causes a great increase in the contact difference of potential. The change is located at the surface of the distilled metal, which becomes more electropositive. A maximum is reached after which the contact potential difference decreases to a steady value which is scarcely affected by the presence or absence of air.

A connexion between these results and some recent work on the photo-electric effect has been pointed out.

The Rice Institute, Houston, Texas.

May 30th, 1914.

XLI. Disintegration of the Aluminium Cathode. By L. L. Campieili *

TN 1891 Crookes $\dagger$ made the first quantitative determi1 nation of the rate of disintegration, or "electrical evaporation," as he termed it, of a number of metals used as cathodes in discharge-tubes containing rarefied air. $\mathrm{He}$ found that the following series represented the relative rate of disintegration of the cathode, in descending order : $\mathrm{Pd}$, $\mathrm{Au}, \mathrm{Ag}, \mathrm{Pb}, \mathrm{Sn}, \mathrm{Pt}, \mathrm{Cu}, \mathrm{Cd}, \mathrm{Ni}$, Ir, Fe. The disintegration of the $\mathrm{Al}$ and $\mathrm{Mg}$ cathodes he found to be zero. This lack of disintegration, or "spluttering," on the part of the aluminium cathode has made its use in spectrum and other discharge-tubes very general.

Shortly after the discovery of the noble, or monatomic gases, argon, helium, neon, xenon, krypton, it was found by Crookes $\ddagger$, Travers $\$$, Baly $\|$, Soddy and McKenzie f, Claude **, and others, that the aluminium cathode

* Communicated by Sir J. J. Thomson, O.M., F.R.S.

† Proc. Roy. Soc. l. p. 88 (1891).

$\ddagger$ Zeitschr.f. phys. Chemie, xvi. p. 370 (1895).

\$ Proc. Roy. Soc. lx. p. 449 (1897).

|| Ibid. lxxii. p. 84 (1903).

T Ibid. Ixxx. Ser. A, p. 92 (1908).

** Compt. Rend. cliii. p. 713 (1911). 